\title{
INVESTIGATING THE EFFECT OF VIBRATION ON THE STABILITY OF THE THREE-WHEELED SCOOTER TAXI
}

\author{
S. J. Ojolo', O. O. Ajayi ${ }^{2}$ and G. A. Asuelinmen ${ }^{3, *}$ \\ $\mathbf{1 , 2 , 3}$, DePt OF MeChaniCAL ENGINEERING, UNIVERSITY OF LAGOS, AKOKA - YABA. LAGOS STATE, NIGERIA \\ E-mail addresses: ${ }^{1}$ ojolosunday@yahoo.com, ${ }^{2}$ bosun_ajayi@yahoo.com, ${ }^{3}$ asuegeo@gmail.com
}

\section{ABSTRACT}

The present three wheeled scooter taxi (TWST) that are widespread in Africa and Asian Countries are fuel economical and inexpensive. However, they are unstable due to their schematic layout. This instability places limitation on the usage of the vehicle. Researchers have investigated the rollover and lateral stabilities of this vehicle, including the effect of vibration on the comfort of the riders. However, not much work has been done on the impact of vibration on the stability of the vehicle. These instabilities could be induced by trenches, potholes, uneven and ungraded roads that are prevalent in developing countries. Therefore, this work modelled and analysed the effect of vibration on a TWST using a standard road bump as reference point. The results proved the vehicle to be unstable in the vicinity of excitation frequency of $15.95 \mathrm{rad} / \mathrm{sec}$ and spring constant of $68,600 \mathrm{~N} / \mathrm{m}$ due to resonance. This would affect safety of life and property. Therefore, it would be appropriate for some of the manufacturers of these vehicles to provide for enough safety margins in the design and selection of springs where the vehicles are rollover and laterally unstable. This will enhance the vehicle safety and receptivity.

Keywords: Three wheeled Vehicle, Vibration Modelling and Analysis, Design, Safety of Life and Property

\section{INTRODUCTION}

Three-wheeled vehicle (TWV) usage, in different countries, varies widely. In developed nations such as United States of America and Canada, they are used mainly for recreation purposes such as shopping, racing and exercises and while in developing countries they are used mainly for commercial purposes [1-5]. Tricycles are either motorised or powered through pedals. They are also used by paraplegics [6].

According to history, the first known TWV or trike was developed by a German paraplegic called Stephan Farffler, in 1655 [7]. He was a horologist that wanted to be transportable. The tricycle was operated by hand cranks. In 1797, French inventors developed a trike powered by pedals. This was followed by series of inventions and development of tricycle in Britain in $19^{\text {th }}$ century with different models produced by different manufacturers [7].

In recent decades, the global economy suffered series of downward trends, leading to unemployment worldwide. As a result, the commercial TWV, called three-wheeled scooter taxi (TWST) shown schematically in Figure 1, was introduced into the third world economy in the nineteen eighties as a means of reducing unemployment and poverty in urban environments $[1,8]$.

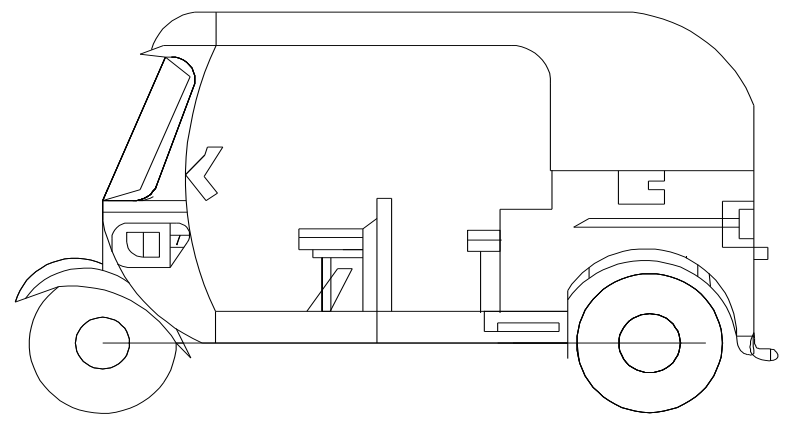

Figure 1: Schematic Diagram of Three-wheeled Scooter (TWST)

However, the firmness of the vehicle on ground has been the main concern [1-4, 9-11]. Many researchers have investigated the rollover and lateral stabilities of the vehicle including the effect of vibration on the

\footnotetext{
* Corresponding author, tel: +234-803- 725 - 5380
} 
comfort of the riders $[1-6,12]$. However, not much work has been done on the impact of vibration on the stability of the vehicle. The instability could be induced by unbalanced wheel, potholes, unfilled trenches, bridge gaps, road bumps and humps, and uneven and ungraded roads [13] which these vehicles have to transverse daily, especially in developing economies.

The focus of this paper is to investigate the effect of vibration on the stability of TWST due to these factors, using standard road bumps as reference point, so as to avoid some of the possible negative impact on the rollover and lateral instabilities of the vehicle [1 - 4].

These factors induce amplitudes which could cause the vehicle to be unstable. However, road bumps are effective charmers of traffic in urban environments, thereby reducing pedestrian road accidents [14]. Nevertheless, improperly designed road bumps and vehicle suspensions, and uneven and ungraded roads coupled with excessive speeds could be inimical to commuters' safety.

\section{MATERIALS AND METHODS}

In this section, mathematical models for the analysis of vibration of Three-Wheeled Vehicle (TWV) were developed with the analytical solution method taken into consideration.

\subsection{Six degree-of-freedom System Forced Vibration Modelling}

Vibration in dynamics has some effect on vehicle stability. In this subsection, six degree-of-freedom system vibration model was derived. It is assumed that vehicle body can only vibrate in $x$-direction, roll and pitch in $y$ and z-directions respectively as shown in Figure 2. Also, the three wheels can only vibrate in x-direction. These make a total of six degree-offreedom model. Mathematical model formulations involved the use of schematic models and free-body diagrams, Newton's and Euler's equations (force and torque equations). Shown in Figure 2 is a schematic model of TWV with six degree-of-freedom vibration. Shown in Figure 3 is a full suspension for TWV based on Figure 2 , with $m_{1}$ as the mass of the body and $m_{2}$ as mass of each wheel as they are assumed to be the same. The wheels are assumed to have different excitation at any point in time due to road contours that are not uniform. Shown in Figure 4 is a freebody-diagram of the full suspension of a TWV based on Figure 3.

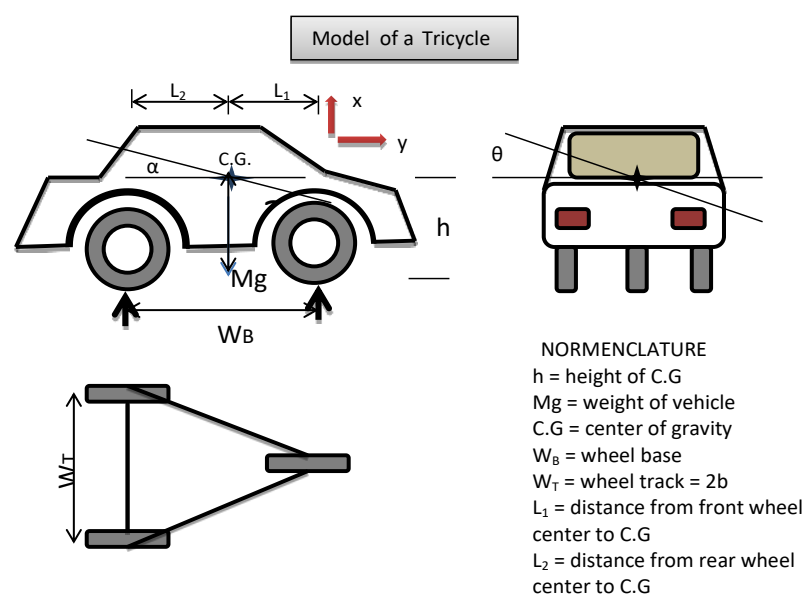

Fig. 2: Six degree-of-freedom Three-Wheeled Vehicle Model

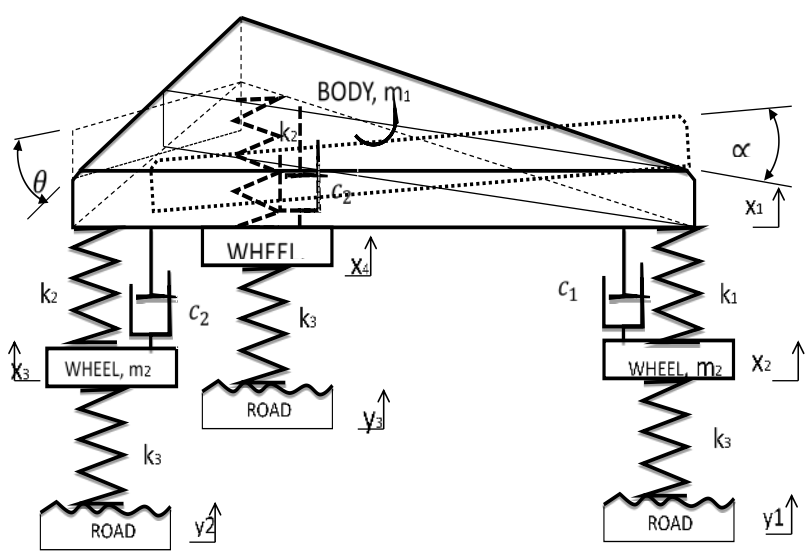

Fig. 3: Six degree-of-freedom of Suspension of a TWV

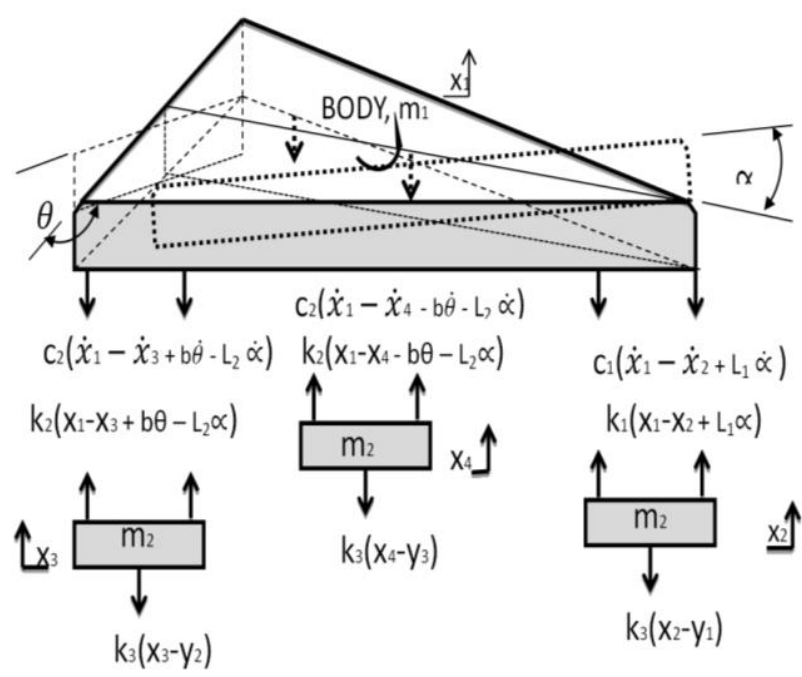

Fig. 4: Six degree-of-freedom Free-Body-Diagram of Suspension of a TWV

Equations (1) to (6) show the governing differential equations of a TWV for forced vibration that was derived, using Newton's and Euler's Equations and the Free-body-diagram shown in Figure 4: 
$m_{1} \ddot{x}_{1}+k_{1}\left(x_{1}-x_{2}+L_{1} \propto\right)+k_{2}\left(x_{1}-x_{4}-b \theta-L_{2} \propto\right)+$

$k_{2}\left(x_{1}-x_{3}+b \theta-L_{2} \alpha\right)+c_{1}\left(\dot{x}_{1}-\dot{x}_{2}+L_{1} \dot{\alpha}\right)+c_{2}\left(\dot{x}_{1}-\right.$

$\left.\dot{x}_{4}-b \dot{\theta}-L_{2} \dot{\alpha}\right)+c_{2}\left(\dot{x}_{1}-\dot{x}_{3}+b \dot{\theta}-L_{2} \dot{\alpha}\right)=0$

$I_{x x} \ddot{\theta}-b k_{2}\left(x_{1}-x_{4}-b \theta-L_{2} \propto\right)+b k_{2}\left(x_{1}-x_{3}+b \theta-\right.$

$\left.L_{2} \propto\right)-b c_{2}\left(\dot{x}_{1}-\dot{x}_{4}-b \dot{\theta}-L_{2} \dot{\alpha}\right)+b c_{2}\left(\dot{x}_{1}-\dot{x}_{3}+b \dot{\theta}-\right.$

$\left.L_{2} \dot{\alpha}\right)=0$

$I_{y y} \ddot{\propto}+L_{1} k_{1}\left(x_{1}-x_{2}+L_{1} \propto\right)-L_{2} k_{2}\left(x_{1}-x_{4}-b \theta-\right.$

$\left.L_{2} \propto\right)-L_{2} k_{2}\left(x_{1}-x_{3}+b \theta-L_{2} \propto\right)+L_{1} c_{1}\left(\dot{x}_{1}-\dot{x}_{2}+L_{1} \dot{\alpha}\right.$

) - $L_{2} c_{2}\left(\dot{x}_{1}-\dot{x}_{4}-b \dot{\theta}-L_{2} \dot{\alpha}\right)-L_{2} c_{2}\left(\dot{x}_{1}-\dot{x}_{3}+b \dot{\theta}-L_{2}\right.$

$\dot{\alpha})=0$

$m_{2} \ddot{x}_{2}-k_{1}\left(x_{1}-x_{2}+L_{1} \propto\right)-c_{1}\left(\dot{x}_{1}-\dot{x}_{2}+L_{1} \dot{\alpha}\right)+k_{3}\left(x_{2}\right.$

$\left.-y_{1}\right)=0$

$m_{2} \ddot{x}_{3}-k_{2}\left(x_{1}-x_{3}+b \theta-L_{2} \alpha\right)-c_{2}\left(\dot{x}_{1}-\dot{x}_{3}+b \dot{\theta}-L_{2} \dot{\alpha}\right)$

$+k_{3}\left(x_{3}-y_{2}\right)=0$

$m_{2} \ddot{x}_{4}-k_{2}\left(x_{1}-x_{4}-b \theta-L_{2} \propto\right)-c_{2}\left(\dot{x}_{1}-\dot{x}_{4}-b \dot{\boldsymbol{\theta}}-L_{2} \dot{\alpha}\right)$

$+k_{3}\left(x_{4}-y_{3}\right)=0$

\subsection{Analysis of the Effect of Vibration due to Bumpy-Roads on the Stability of TWST}

The three parameters that are of interest under multi-bodies vibration dynamics are: Amplitude, Acceleration and Frequency. The effect of amplitude is to cause rollover, slip or slid of a vehicle. Moreover, it could generate gyroscopic couple and Coriolis acceleration, with their attendant negative affect on lateral stability $[13,15]$.

It is assumed that if the front wheel or the two rear wheels of a TWV are ridden over a road bump-likeobstacle on the roads that it cannot induce rollover instability. However, if one of rear wheels rides over the obstacle that it can induced rollover instability to the vehicle. If the roll and pitch movement of the vehicle body are neglected, the governing sixdegree-of-freedom differential equations derived as shown in equations (1) to (6) can be reduced to twodegree-of-freedom for forced vibration, on any of the rear wheels as shown in Figure 5.

Equations (7) and (8) were derived based on the free body diagram in Figure 5 as follows:

$$
m_{1} \ddot{x}_{1}+k_{1}\left(x_{1}-x_{2}\right)+c_{1}\left(\dot{x}_{1}-\dot{x}_{2}\right)=0
$$$$
m_{2} \ddot{x}_{2}-k_{1}\left(x_{1}-x_{2}\right)-c_{1}\left(\dot{x}_{1}-\dot{x}_{2}\right)+k_{2}\left(x_{2}\right)=F \sin w
$$

Where $k_{2} x_{3}$ can be expressed as $F \sin w t$

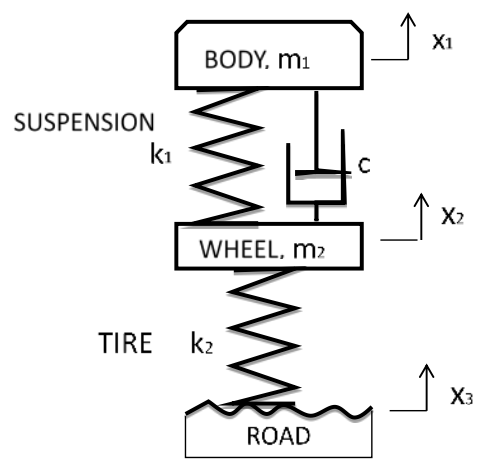

Free Body Diagram

Fig. 5: Two-Degree-of-Freedom Vibration Model for TWV

Equations (7) and (8) can be expressed in matrix form:

$$
\begin{aligned}
{\left[\begin{array}{cc}
m_{1} & 0 \\
0 & m_{2}
\end{array}\right]\left(\begin{array}{l}
\ddot{x}_{1} \\
\ddot{x}_{2}
\end{array}\right)+} & {\left[\begin{array}{cc}
c_{1} & -c_{1} \\
-c_{1} & c_{1}
\end{array}\right]\left(\begin{array}{l}
\dot{x}_{1} \\
\dot{x}_{2}
\end{array}\right) } \\
& +\left[\begin{array}{cc}
k_{1} & -k_{1} \\
-k_{1} & k_{1}+k_{2}
\end{array}\right]\left(\begin{array}{l}
x_{1} \\
x_{2}
\end{array}\right) \\
& =\left[\begin{array}{c}
0 \\
F \sin w t
\end{array}\right]
\end{aligned}
$$

The Dutch guideline created by Richtlijn drempels, plateaus un uitritten - CROW for traffic bump design (similar to other internationally acceptable standards) is stated in Equation (10) [14]:

$$
x=\frac{H}{2}\left[1-\cos \left(\frac{2 \pi v}{L}\right)\right]
$$

Where $\mathrm{H}$ is the height of bump $(0.12 \mathrm{~m}), \mathrm{L}$ is the length of bump (4.8m) and speed of the vehicle $v$ is $50 \mathrm{~km} / \mathrm{hr}[6]$.

The equation (10) is simplified to (since initial value is $\left.-\frac{H}{2}\right)$ :

$x=\frac{H}{2}\left[\sin \left(\frac{2 \pi v}{L}-\frac{\pi}{2}\right)\right]=-\frac{H}{2}\left[\cos \left(\frac{2 \pi v}{L}\right)\right]$

$=-\frac{H}{2}[\cos (\omega t)]$

Where the angular velocity of the bump is:

$\omega=\frac{2 \pi V}{L}=\frac{\left[2 \pi\left(\frac{50}{3.6}\right)\right]}{4.8}=18.18 \mathrm{rad} / \mathrm{s}$

To find the equations of motion within 0 and $2 \pi$ for Forced vibration. Initial Conditions for the road excitation are: When $\mathrm{t}=0, X_{3}=-\frac{H}{2}=-0.06, \dot{X}_{3}=$ 0

The harmonic bump excitation equation can be written based on Equation (11) as:

$x_{3}=X_{3}[\cos (\omega t)]$

The imposed general solution of steady-state harmonic excitation is of the form stated in Equations (14-16) [16-18] for the vehicle body, the rear wheel and the body relative to the rear wheel respectively: $x_{1}=X_{1} \cos \left(\omega t-\varphi_{1}\right)$

$x_{2}=X_{2} \cos \left(\omega t-\varphi_{2}\right)$ 
$x_{1}-x_{2}=x_{4}=X_{4} \cos \left(\omega t-\varphi_{4}\right)$

Some parameters derived from equations (7) and

(8) are extracted from study of [17] as:

$$
\begin{gathered}
\epsilon=\frac{m_{1}}{m_{2}} \\
\omega_{1}=\sqrt{\frac{k_{1}}{m_{1}}} \\
\omega_{2}=\sqrt{\frac{k_{2}}{m_{2}}} \\
\propto=\frac{\omega_{1}}{\omega_{2}} \\
\gamma=\frac{\omega}{\omega_{1}} \\
w_{1}=\frac{c}{2 m_{1} \omega_{1}} \\
w_{2}=2 \xi \gamma\left[\left(1-\{1+\epsilon\} \gamma^{2} \alpha^{2}\right)\right] \\
\gamma^{2}=\frac{4 \xi^{2} \gamma^{2}+1}{w_{1}^{2}+w_{2}^{2}} \\
\tau^{2}=\frac{4 \xi^{2} \gamma^{2}+1+\gamma^{2}\left(\gamma^{2}-2\right)}{w_{1}^{2}+w_{2}^{2}} \\
\eta^{2}=\frac{\gamma^{4}}{w_{1}^{2}+w_{2}^{2}}
\end{gathered}
$$

The solutions are given as:

$$
x_{1}=X_{1} \cos \left(\omega t-\varphi_{1}\right)=\mu X_{3} \cos \left(\omega t-\varphi_{1}\right)
$$

Therefore, from equation:

$$
\varphi_{1}=\cos ^{-1}\left(\frac{X_{3}}{X_{1}}\right)
$$

$$
\begin{gathered}
x_{2}=X_{2} \cos \left(\omega t-\varphi_{2}\right)=\tau X_{3} \cos \left(\omega t-\varphi_{2}\right) \\
x_{4}=x_{1}-x_{2}=X_{4} \cos \left(\omega t-\varphi_{5}\right) \\
=\eta X_{3} \cos \left(\omega t-\varphi_{4}\right)
\end{gathered}
$$

Using parametric values from open literature of [2, $5,10,20,21]$, the amplitudes of vibration of a TWST body were computed for various loadings and spring constants using Microsoft Excel 2010, based on equations $(28-31)[17,18]$.

\section{RESULTS AND DISCUSSION}

\subsection{Parametric Values}

\begin{tabular}{|c|c|c|c|}
\hline Parameter & Symbol & Value & Source \\
\hline \multirow{5}{*}{ Rear weight $x 0.5$ less Mass of Rear Wheel } & \multirow{5}{*}{$\mathrm{m}_{1}$} & $114.7 \mathrm{~kg}$ & \multirow{5}{*}[4]{} \\
\hline & & $131.7 \mathrm{~kg}$ & \\
\hline & & $160.7 \mathrm{~kg}$ & \\
\hline & & $190.2 \mathrm{~kg}$ & \\
\hline & & $219.7 \mathrm{~kg}$ & \\
\hline Mass of Wheel & $\mathrm{m}_{2}$ & $7 \mathrm{~kg}$ & By Experiment \\
\hline Mass of Wheel (may include: shaft and drum) & $\mathrm{m}_{2}$ & $10.3 \mathrm{~kg}$ & [9] \\
\hline Spring constant for rear spring & \multirow{3}{*}{ k1 } & $\begin{array}{l}50,400 \mathrm{~N} / \mathrm{m}(\mathrm{kd}) \text { and } 49,800 \\
\mathrm{~N} / \mathrm{m}(\mathrm{kc})\end{array}$ & {$[19,20]$} \\
\hline Spring constant for rear spring & & $\begin{array}{l}44,100 \mathrm{~N} / \mathrm{m}(\mathrm{ka}) \text { and } \\
68,600 \mathrm{Nm}(\mathrm{ke})\end{array}$ & {$[1]$} \\
\hline Spring constant for rear spring & & $48,000 \mathrm{~N} / \mathrm{m}(\mathrm{kb})$ & [9] \\
\hline Tire stiffness rear left or right & $\mathrm{k} 2$ & $250,490 \mathrm{~N} / \mathrm{m}$ & {$[1]$} \\
\hline $\begin{array}{l}\text { Hydraulic double acting shock absorber Rear } \\
\text { (Left or Right) }\end{array}$ & $\mathrm{C}$ & 2,207.5 Ns/m & {$[19,20]$} \\
\hline Road Bump Excitation Frequency Computed & $\omega$ & $15.95 \mathrm{Rad} / \mathrm{sec}$ & {$[1]$} \\
\hline
\end{tabular}

Shown in Table 1 are parametric values used in obtaining the results.

\subsection{Results of Two Degrees-of-Freedom System Dynamics Model over Standard Road Bump-like-Obstacle}

Figure 6 shows that the vehicle body and the wheel lag behind the road profile by about $64^{\circ}$ and $43.71^{\circ}$ respectively. The implication of this is that the body and wheel could not respond to road profile immediately. There are time lags due to spring and wheel compressions. The wheel will take up first before the body. Nonetheless, their meeting point is at the peak of the road profile, in a deceasing manner, with the vehicle body attaining unto the highest amplitude during the cycle.

Table 1: Parametric values 


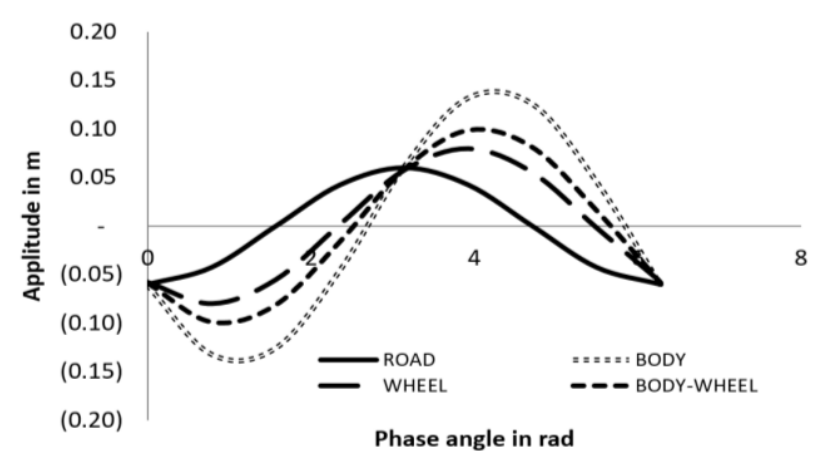

Figure 6: Amplitude of force vibration over one complete cycle due to standard bump

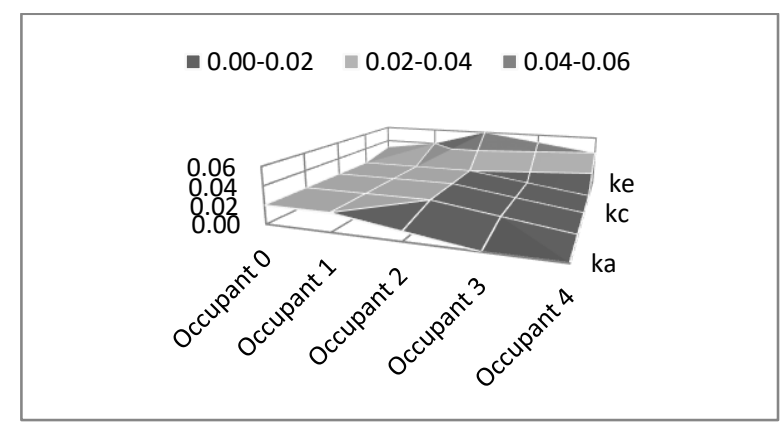

Figure 7: Amplitude versus occupants with $15.95 \mathrm{rad} / \mathrm{s}$ and $10.3 \mathrm{~kg}$ whee/ weight

Shown in Figures 7-10 are the amplitudes of the vehicle body due to vibration, over two different bump profiles, with two different rear wheel weights and varying spring constants based on Table 1 and equation (12). All the amplitudes were reduced by $0.08 \mathrm{~m}$ for plot clarity purposes.

It is expected that the higher the spring constant and the more the load, the less would the amplitude of vibration. However, as can be observed from Figure 7-10 this is not the case. The reason is that the closer the natural frequency of vehicle is to that of road excitation, the higher the amplitude and the further the less. The amplitude of vibration increases towards the resonant frequency and thereafter begins to decrease.

From Figures 7 and 8 increase or decrease of the front wheel weight relative to the vehicle body weight has no much effect on amplitude of vibration of the vehicle. The same thing is applicable in Figures 9 and 10. It can be concluded that change in wheel weight has no significant effect on amplitude of vibration.

However, changes in frequencies of wheels over bumps do affect amplitude of vibration, as can be seen from Figure 7 and 8 when compared with Figures 9 and 10 .

The implication of this is that vehicle designers should select appropriate spring in line with international standard bumps and local realities to minimize effect of resonance frequency, so as to avoid its negative impact on the vehicle stability. The average rollover angle of TWST that causes instability is $28^{\circ}$ [3] which amounts to lifting one of rear wheels by about $0.30 \mathrm{~m}$.

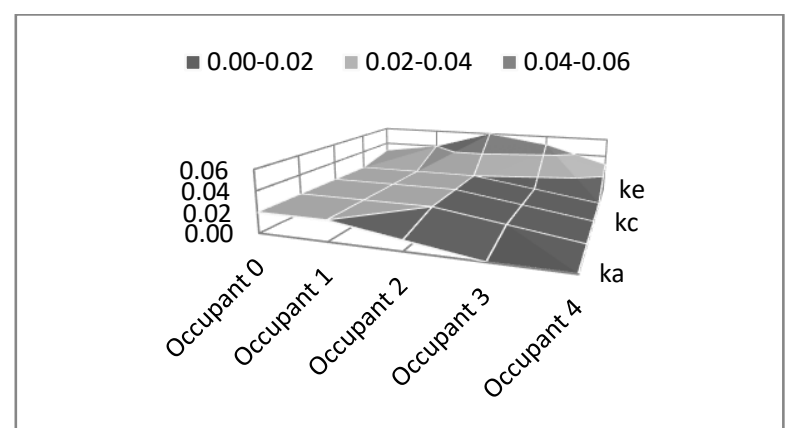

Figure 8: Amplitude versus occupants with $15.95 \mathrm{rad} / \mathrm{s}$ and $7 \mathrm{~kg}$ wheel weight
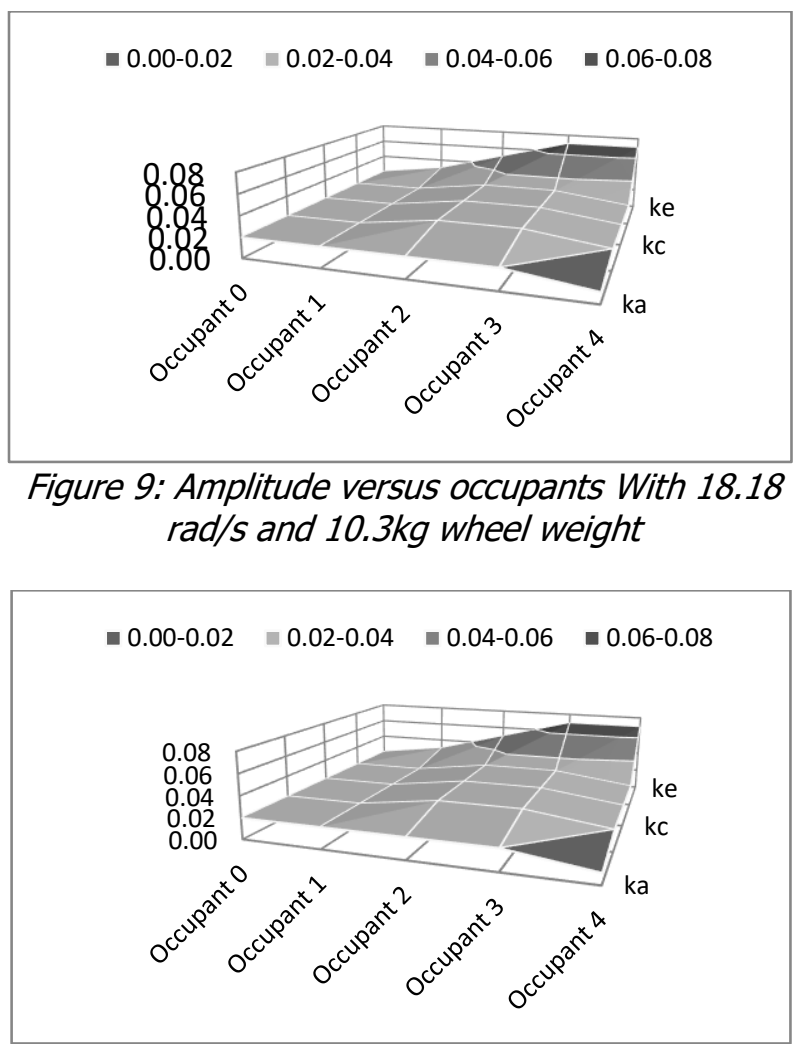

Figure 10: Amplitude versus occupants With 18.18 $\mathrm{rad} / \mathrm{s}$ and $7 \mathrm{~kg}$ wheel weight

From the results based on Figures 7 - 10 the maximum amplitude of the vehicle body is about $0.15 \mathrm{~m}$, which is approximately $0.3 \mathrm{~m}$ lift due to the road profiles on any of the rear wheels. As a result, climbing over standard bumpy-roads the vehicle will not be too safe in terms of rollover stability with 3 or 4 occupants, using spring constant of $68,600 \mathrm{~N} / \mathrm{m}$. Bump profile of $15.95 \mathrm{rad} / \mathrm{sec}$ would be worse. However, with spring constant range of $48,000 \mathrm{~N} / \mathrm{m}$ to $51,000 \mathrm{~N} / \mathrm{m}$ over standard bumpy-roads, the vehicle will be safe for the two excitation frequencies.

\section{CONCLUSION}

This study came up with six degree-of-freedom vibration model for the determination of stability of TWV in order to enhance safety of life and property.

The model was used in the analysis of the rollover stability of one of the familiar TWST on African and Asian roads 
based on standard road bump-like profiles. The vehicle was found to be rollover unstable with three to four occupants by climbing over a bump-like profile of $15.95 \mathrm{rad} / \mathrm{sec}$ with spring constant of $68,600 \mathrm{~N} / \mathrm{m}$ on one of the rear wheels. However, with spring constant range $48,000 \mathrm{~N} / \mathrm{m}$ to $51,000 \mathrm{~N} / \mathrm{m}$ over these bump-like profiles the vehicle will be safe. The implication of this is that vehicle designers should select appropriate springs in line with international standard bumps and local realities to minimize effect of resonance frequencies, so as to avoid their negative impact on the vehicle stability.

In addition, gyroscopic couple would be developed due to oscillation of the rear axle of the vehicle by bumps, uneven and ungraded roads, while in motion, which could induce lateral instability to the vehicle [13]. Nonetheless, it can be reduced on the TWST by introducing tyres with higher cornering coefficient at the rear [4]. Else, the vehicle should be redesigned to take care of rollover and lateral stabilities, and the effect of resonance frequencies.

\section{REFERENCES}

[1]. Gawade, T. R., Mukherjee, S. and Mohan, D. "Sixdegree-of-freedom three-Wheeled-vehicle model validation", Journal Automobile Engineering, 219(4): 487-498, 2005.

[2]. Mukherjee, S., Mohan, and Gawade, T. R. "Threewheeled scotter taxi: A safety analysis", Sadhand Vol. 32, pp. 459-478, 2007.

[3]. Ojolo, S. J., Ajayi, O. O. and Asuelinmen G. A. "Rollover Stability Models For Three-Wheeled Vehicle Design", Arid Zone Journal of Engineering, Technology and Environment (AZOJETE), Vol. 16, pp. 92 - 99, 2020.

[4]. Asuelinmen, G. A., Ojolo, S. J., and Ajayi, O. O. "Investigating the Lateral Stability of ThreeWheeled Scooter Taxi due to Tyre-Road Forces", Nigerian Journal of Technology (NIJOTECH), Vol. 39, No. 1, pp. 189 - 195, 2020.

[5]. Ihueze, C. C. and Ebisike, P. S. "Dynamic Analysis of Instability in Three-Wheeler Automobile Vehicle", Archives of Current Research International, 13(3): 1-10, 2018; Article no.ACRI.38801, 2018.

[6]. Ayodeji, S. P. and Adejuyigbe, S. B. "Computer Aided Design and Development of Tricycle for Paraplegics Using Anthropometric Parameters", Retrieved November 21, 2012, from http://dspace.futa.edu.ng:8080/jspui/handle/123 456789/2930: htt://dspace.edu.ng., 2009.

[7]. Bicycle History, "Tricycle History, Facts and Types", Available at: Bicycle History: http://www.bicyclehistory.net>history-of..., Retrieved June 29, 2020.

[8]. Mgbemena, J. "Language, communication on wheels and national development: the inscriptions on tricycle (Keke) example", International Journal of English and Literature, Vol. 4(10), pp. 529-537, 2013.

[9]. Karanam, V. M., Chatterjee, A. and Ghosal, A. " Procedural aspects of modelling the dynamics of a three wheeled vehicle using Adams-Car", India Institute of Science,[online]. Available at: http://epints.iisc.ernet.in/40423/ , Accessed: November 2019.

[10]. Berote, J. and et. al, "The Dynamics of a Threewheeled Narrow-Track Tilting Vehicle", University of Bath, UK, 2008.

[11]. Dardaine, J., Rodier, L. and Venaille, V. "Preliminary Study of a Three-wheel Tandem Powered by a PEN Fuel Cell", FISITA 2008 World Automotive Congress, 2008.

[12]. Dizo, J., Blantnicky, M. and Melnik, R. "Assessment of Passenger's Ride Comfort of a Tricycle", Scientific Journal on Tranport and Logistics, Vol. 9 No 2, 2018.

[13]. Giri, N. K. Automobile Mechanic, Delhi: Khanna Publishers, 2006.

[14]. Raemaekers, A. J. "Active Vibration Isolator Design for Ambulance Patient", Eindhoven: Eindhover University of Technology, 2009.

[15]. Meriam, J. L. and Kraige, L. G. Dynamics, New York: John Wiley \& Sons, Inc., 2004

[16]. Rao, S. S. Mechanical Vibrations, New Delhi: New Age International (P) Limited, Chapter 13:1-75, 2010.

[17]. Jazar, N. J. Vehicle Dynamics, Springer Science+Business Media, LLC, New York, 2008.

[18]. Kelly, S. G. Mechanical Vibrations, New York: Schaum's Outline Series, McGraw-Hill, 1996.

[19]. Bajaj Auto Richshaw Bajaj Auto Richshaw tuk-tuk three wheelers passengertricycle BA175ZK, Retrieved September 25, 2012, from Bajaj Auto Richshaw: http://www.bajaj-auto-richshaw.com, 2012.

[20]. Rao, L. V. and Chinta, P. P. "Dynamic Behaviour of Three-wheeler Passenger Vehicle Using Finite Element Method, Rigid Body Modelling and Comparison with Intelligent Design Automation", National Monthly Refereed Journal of Research in Science and Technology, Vol. 2, No. 8, pp. 45-55, 2014. 